\title{
El arte desde América Latina. \\ La danza contemporánea y el recurso del cuerpo como discurso.
}

Las nuevas escrituras escénicas

Iván Ontiveros-Ontiveros

Universidad Autónoma de Nuevo León

México

Recibido: 11 julio de 2019

Aceptado: 20 de diciembre 2019

DOI: https://doi.org/10.15359/tdna.36-67.1

\section{Resumen}

El cuerpo es una herramienta para el artista como lo es la espátula para el escultor o serrucho para el carpintero. Aunque esta afirmación es muy simple, la verdad es que en la práctica hay una brecha amplia entre el arte y el oficio. Y dentro de esta brecha es donde me interesa colocar el cuerpo como una herramienta de discurso para el lenguaje de la danza contemporánea

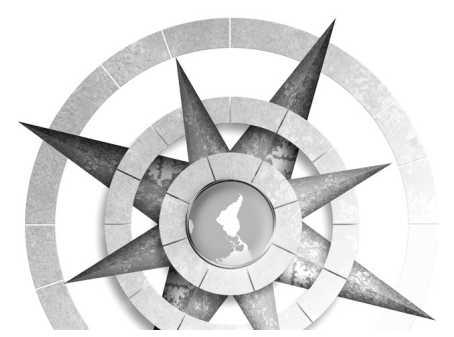

Palabras claves: danza, cuerpo, discurso, arte latinoamericano
Abstract
The body is a tool for the artist as is the spatula for the sculptor or saw for the carpenter. Although this statement is very simple, the truth is that in practice there is a wide gap between art and craft. It is within this gap that I am interested in placing the body as a tool of discourse for the lan- guage of contemporary dance.
Keywords: Contemporary dance, body, discourse, Latin American art

\section{Resumo}

O corpo é uma ferramenta para o artista, assim como a espátula para o escultor ou a serra para o 
carpinteiro. Se bem que esta afirmação seja muito ingénua, a verdade é que, na prática, existe um grande fosso entre a arte e o ofício. É dentro desta lacuna o que me interessa colocar o corpo como um instrumento de discurso para a linguagem da dança contemporânea

Palavras chave: dança contemporânea, corpo, discurso, arte latino-americana

En este ensayo reflexionamos sobre los cuestionamientos que plantea la poética territorial del cuerpo del bailarín en el escenario y cómo la danza contemporánea ha desplazado su mirada hacia otras disciplinas artísticas, de-construyendo y re-significando el espacio en su búsqueda por crear artificios innovadores. Discutiremos cómo el cuerpo en escena se ha ido reinventando en un sinfín de maneras al ocupar el escenario con nuevos horizontes planteados desde diversas disciplinas y campos. Tomaremos algunos de los escritos del ensayista portugués José Gil (2015), en particular el artículo "La paradoja del cuerpo”, al igual que algunas obras de artistas escénicos contemporáneos, con el fin de problematizar el rol del cuerpo en un espacio escénico y la potencia y poética de este. Por ello, habría que iniciar con varios cuestionamientos que se proponen a continuación para iniciar el diálogo.

¿Qué sucede cuando el cuerpo de un bailarín baila en la escena? En el campo real, el cuerpo suda, los órganos se activan, la endorfina y la dopamina estallan en el sistema, las extremidades y el tronco del cuerpo circulan consciente $\mathrm{e}$ inconscientemente a un ritmo particular. En el campo virtual, el cuerpo se convierte en una prótesis para el espacio transformado a su vez, se ofrece al espectador como una plataforma de un diálogo oculto, o por decirlo de otra manera, más allá de las palabras; las sensaciones que acontecen en el cuerpo del bailarín, dependiendo de cada ser humano, se gesticulan en un tiempo alterno diferente al cotidiano, pues las pautas de dirección del movimiento responden a otros campos de decisión y los conocimientos arraigados en el cuerpo de un bailarín se desdoblan en esa superficie entre la piel y el espacio, para ofrecer una plasticidad única de acuerdo con cada intérprete.

Como sabemos, todos estos acontecimientos que suceden en el bailarín mientras baila ocurren en un tiempo y un espacio determinados por el propio bailarín, a los cuales como espectadores nos sujetamos para contemplar y/o para analizar. De esta manera, lo que ocurre en el acto de ver danza acontece en un campo intangible que denominaremos virtual.

En este campo es donde se pretende el diálogo entre el espectador y el bailarín. Para que esta comunicación ocurra, el coreógrafo desarrolla una labor de 
montaje después habitualmente de una investigación, ya sea de movimiento, temática o semiótica o de cualquiera de las fusiones de estas, o simplemente de algún repertorio ya pautado con anterioridad por el mismo u otro coreógrafo. Luego de esto, el bailarín realiza un trabajo de memoria para lograr una ejecución de acuerdo con las necesidades interpretativas del coreógrafo. Ya en el escenario, el intérprete se convierte en un cuerpo sin adjetivos particulares: el cuerpo que danza es un cuerpo sin nación, es un cuerpo que baila para otros cuerpos. El cuerpo en escena solo puede ejercer un diálogo universal cuando alienta la posibilidad de bailar para cualquier espectador. Solo así el cuerpo ofrece la oportunidad de diálogo. Aún cuando el cuerpo baila en espacios abiertos (al aire libre) o espacios cerrados, el flujo de energía que circula en él y el ritmo que genera con sus movimientos y silencios, llevan al espectador a nuevos lugares perceptivos en tanto texturas y sensaciones.

Idealmente, los cuerpos suelen transformarse encima del escenario, incluso hay bailarines que tienen un manejo del espacio tan sorprendente que llegan a parecer de mayor estatura y esto no responde más que al convenio de prótesis que tienen con el espacio. Tomemos la analogía que José Gil hace del cuerpo en el espacio y la bañera: imaginemos nuestro cuerpo en una tina de baño con agua, si en esta tina de baño colocamos una araña, nuestro cuerpo podrá sentir miedo, asco o cualquier otra sensación con tal intensidad de cercanía gracias al agua y al recipiente. A esto José Gil lo define como el espacio del cuerpo, donde el espacio escénico después de la piel del bailarín es el agua dentro de un recipiente que es el cubo finito del escenario. Aquellos bailarines que transforman sus dimensiones y nos regalan texturas exquisitas operan dentro de este espacio finito, convirtiéndolo en ocasiones en infinito en tanto sensaciones y emociones, con la capacidad de contraer y alargar las distancias en relación con puntos específicos (premeditados o improvisados) en el espacio.

En relación con esto, no hay ejemplos más claros que los bailarines de danza butoh que parece que transforman el espacio con una facilidad de movilidad e inmovilidad que pone a prueba nuestra capacidad de percepción. ${ }^{1}$

Y aunque muchos prodigios de la danza contemporánea nos deslumbran con la plasticidad de su técnica y los coreógrafos nos presentan una diversidad mundial en la manera de hacer danza, al final esto no es más que un indicativo de la necesidad de hablar con el cuerpo desde los diferentes contextos mundiales que se viven. Aun así, existen artistas contemporáneos

1 Walch, R (2006). Butoh Dance Performance in Japan. Recuperado de: https://www.youtube.com/ watch? $=9 \mathrm{~ms} 7 \mathrm{MGs} 2 \mathrm{Nh} 8 \&$ feature=youtu.be 
que se preocupan por acercar cada vez más los cuerpos promedio al escenario para demostrar la capacidad de diálogo entre bailarines profesionales y cuerpos de otras disciplinas y contextos, reapropiándose así de los habituales modelos de producción, generando nuevas metodologías y resultados. Es el caso de algunos directores de teatro y danza contemporáneos que más adelante mencionaré con sus respectivos links.

Todos estos creadores proponen fórmulas de procesos creativos de acuerdo con las necesidades de los proyectos que generan. Incluso hay los que más allá de la preocupación por introducir otros cuerpos no formados por alguna técnica de baile al diálogo entre intérprete y espectador desde el escenario, se adelantan con la idea de generar plataformas de diálogo entre público y público o público y bailarín sobre el escenario en un ejercicio más próximo a un ejercicio sociológico que a un espectáculo. Es el caso del director catalán Roger Bernat, donde la audiencia es quien realiza la coreografía al condicionar el movimiento del público mediante indicaciones que se dan desde unos audífonos.

Así, al representar una coreografía inspirada en la obra La consagración de la primavera de Pina Bausch los presentes realizan la función de coro o de protagonistas mediante las indicaciones dadas. Los espectadores participan en este experimento sociológico donde el campo virtual abre más posibilidades de diálogo del espectador con su propio cuerpo, con el del otro, con el espacio y el contexto. En este campo virtual, el cuerpo del espectador es partícipe de un discurso que sucede a través de su posición en el escenario. Este experimento sucede en un espacio cerrado con una convocatoria publicitaria. Indudablemente, quien sea parte del gremio escénico y conozca el trabajo de Bernat asistirá por el gusto de participar en sus experimentos. ${ }^{2}$

En este sentido, pareciera que sus piezas son exclusivas para este tipo de público, sin embargo, el catalán tiene otra pieza en la que realiza un experimento parecido pero en plazas públicas, sin previa publicidad, así los participantes de la obra no solo son del gremio artístico, sino también transeúntes casuales que circulan por la plaza donde se lleva a cabo la obra. Esta pieza se llama Dominio Público y trata sobre unos reos y unos policías envueltos en un acontecimiento de fuga. ${ }^{3}$

Las preguntas que surgen dentro de estas necesidades de búsqueda de otras alternativas para comprender el

2 Festival 10 sentidos (2014) Entrevista con Roger Bernat sobre 'La consagración de la primavera' IV Festival 10 Sentidos. Recuparado de:https:// www.youtube.com/watch? $=$ dfZUuFasID0

3 Dominio Publico by Roger Bernat (2008) https:// www.youtube.com/watch? ${ }^{=}=\mathrm{ZBnNmLNsLO} 8$

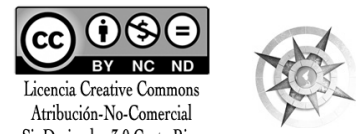


quehacer del arte escénico, nos llevan no a la necesidad de respuestas, sino a la necesidad de más preguntas en relación con el cuerpo y nuestro entorno. El cuerpo que es ya una finitud (es decir, un recipiente con bordes donde habitan nuestros órganos y consciencia), irónicamente es un espacio vacío donde cabe una infinidad de simbolismos y cualquier representación. El espacio del cuerpo, como lo denomina José Gil, es un lugar noble con la posibilidad de habitar cualquier lectura que el espectador necesite moldear consciente e inconscientemente. Por esta razón es tan necesario el acercamiento a otras disciplinas y a otros contextos. Detrás de cada nueva disciplina, detrás de cada nuevo concepto de inter, multi o transdisciplina está el cuerpo. Está el cuerpo exigiendo una relación inmediata con el todo.

\section{Referencias bibliográficas}

Gil, J. (2015). O corpo paradoxal. In Lins, D v Gadelha, S (Orgs), Nietzsche e Deleuze: Que pode o corpo Río de Janeiro: Relume Dmará. 